\title{
Neuropsychological Phenotype in Wolf-Hirschhorn Syndrome
}

\author{
Maria Cristina Cossu, ${ }^{1,2 *}$, Annalisa Albergo ${ }^{2}$, Claudia Galluzzi ${ }^{1}$, Cristiana Stefani ${ }^{1}$ and \\ Gabriella Antonucci ${ }^{1,2}$
}

\author{
${ }^{1}$ I.R.C.C.S Istituto di Ricovero e Cura a Carattere Scientifico "Fondazione Santa Lucia", Roma, Italy \\ ${ }^{2}$ Dipartimento di Psicologia, Università degli Studi di Roma "La Sapienza”, Italy
}

\begin{abstract}
The Wolf-Hirschhorn syndrome (WHS) is a rare genetic disorder that causes a range of intellectual disability from mild to severe. In this study, we used standard tools to psychometrically characterize the specific neuropsychological phenotype of WHS. We studied 57 individuals with WHS, ranging in age from 2.6 to 28.6 years representing $70 \%$ of the certified Italian WHS population. Results obtained by administering Griffiths' Mental Developmental Scales and the Vineland Adaptive Behavior Scale revealed a typical WHS neuropsychological phenotype characterized by specific strengths and weaknesses. Despite their severe cognitive impairment, in both scales, patients showed better communication and social interaction skills compared to visuo-motor abilities.

Results of our study could bring to the development of new and more effective treatments for individuals affected by WHS: based on neuropsychological phenotype description, it should be possible to design specific rehabilitation programs. These programs would then be aimed at improving rehabilitation protocols to optimize the developmental potential and personal independence of individuals with WHS and thus to improve their quality of life.
\end{abstract}

Keywords: Neuropsychological phenotype, intellectual disability, Wolf-Hirschhorn Syndrome, WHS, 4p deletion.

\section{INTRODUCTION}

Wolf-Hirschhorn syndrome (WHS) is a rare genetic disorder that has a strong social impact on patients' families and caregivers, often characterized by significant emotional involvement and constant distress. This is true when the cognitive abilities of patients with WHS are unknown: in fact, frequently this condition is "accepted" [1], and no rehabilitation is undertaken. This situation contrasts with the possibility to develop early, specific rehabilitative interventions aimed to both reinforce the patients' residual cognitive abilities and to make them able to learn and generate adaptive strategies to improve their autonomy. Identifying the neuropsychological phenotype and the specific features of the cognitive impairments of patients with WHS would enable us to develop specific rehabilitation programs and to help to reduce the social stigmatization caused by this disorder.

Although WHS was described at the beginning of the 1960s [2], the true nature of the syndrome was first brought to the attention of the medical-scientific community in 1999 [3]. WHS is normally diagnosed at birth, based on typical clinical signs and genetic testing; rarely, it has also been diagnosed prior to birth $[4,5]$.

WHS is considered a contiguous gene syndrome caused by partial alteration of the distal extremity of the

*Address correspondence to this author at the Fondazione I.R.C.C.S Santa Lucia, Neuropsicologia, Via Ardeatina, 306; Cap. 00179, Rome, Italy; Tel: +39 06 51501110, +39 348 9131554; E-mail: mc.cossu@hsantalucia.it,

mccossunps@libero.it short arm of chromosome 4 [6]. Many patients are affected by a $4 p$ deletion $[7,8]$. In fact, cases (10-15\%) of derivative chromosome 4 originating from a parental balanced translocation $[9,10]$ or mosaicism [11] have been reported.

Since the 1980s, the prevalence of WHS has been estimated as $1 / 50,000$ births [12], with a female to male ratio of $2: 1$ [3]. A study published in U.K. [13] estimated that the frequency was between $1 / 50,000$ and $1 / 95,896$ births. More recently, a study by Maas et al. [14] reported that the incidence of WHS was similar to that of Angelman syndrome, which is about $1 / 20,000$ births.

WHS is characterized by prenatal and postnatal growth delay $[15,16,17]$, typical facial dysmorphism $[18,19]$, multiple congenital malformations which can affect any organ or apparatus [3,20,21,22], neurological deficits $[23,24,25]$, and intellectual disability [26,27]. Neurological deficits consist of congenital hypotonia and, in more than $90 \%$ of cases, the onset of seizures occurs within the first three years of life. Seizures are often associated with disrupted sleep patterns [28, 29].

Individuals affected by WHS also present psychomotor and cognitive delay symptoms [3, 30, 31, 32]. In the past, overall neuropsychological impairment was considered to range from severe to profound. From the late 1990s, however, patients with better developmental levels have been identified [1, 33, 34, 35]. Although these studies confirm that intellectual disability is always present in WHS, no further information is offered concerning the nature or the degree of cognitive impairment. 
More recently, however, a few studies systematically analyzed the specific characteristics of the neuropsychological profile of WHS using reliable psychometric procedures [3, 30, 31, 36, 44]. Although the patients' samples examined and the procedures were different, results seem to lead to the identification of a typical WHS cognitive-behavioral profile: patients exhibited some strength in socialization abilities and communicative skills.

In this study, we aimed to obtain further understanding about WHS and to define it by means of psychometric analysis. As far as we believe that a comprehensive assessment must contain a measurements of the actual cognitive domains and of the adaptive behavior; we decided to evaluate developmental level using the Griffiths Scales [37, 38] and to evaluate the adaptive behavior using the Vineland Adaptive Behavior Scales [39]. Results of our study could bring to the development of new specific treatments for individuals affected by WHS, which would then be aimed at improving rehabilitation protocols to optimize the development and independence of WHS individuals and thus to improve quality of life.

\section{ETHICS APPROVAL}

The present study is part of the I.R.C.C.S. S. Lucia Foundation's Current Research. Approval for the study was obtained from the Foundation's independent Ethics Committee.

\section{METHODS}

Subjects were recruited with the assistance of the Italian Wolf-Hirschhorn syndrome Association (AISIWH) and national referral physicians for WHS. At present, 81 individuals with WHS have been identified in Italy. This study comprised 57 individuals (33 females and 24 males, aged from 2.6 to 28.6 years; mean age $12.6 \pm 6.75$ years).
Inclusion criteria were based on a genetic diagnosis confirmed by specific examination and on subjects aged over 30 months. Deletions were detected by standard cytogenetic analysis (36 patients: kariotype) or by fluorescence in situ hybridization (21 patient fisch-test). 42 patients were treated with antiepileptic medications; 15 not treated subjects did not have or stopped having seizures before our evaluation.

During the study, one subject died and another did not complete the evaluation, therefore their data were excluded from the analyses. In the final sample, ages ranged from 2.9 and 27.2 years (median=12.4). Given the wide range of age, the whole sample was divided into three cohorts $(2-8,9-17,18-28$ years) in order to assess the age impact on the cognitive behavioral scores. Demographical characteristics according to age cohorts and gender are reported in Table $\mathbf{1}$

\section{MATERIALS}

The following psychometric instruments were used to determine the WHS neuropsychological phenotype:

1) Griffiths Scales were first published in 1970, and revised by the same authors in 1984 . This is one of the most commonly used instruments to investigate various domains of neuropsychological development with children from 0 to 8 years of age, but it has also been used with older individuals whit intellectual disability $[40,41]$. The instrument is comprised of six different scales each one assessing the development of specific neuropsychological functions: A) Locomotor scale, B) Personal social scale, C) Hearing and language scale, D) Coordination scale, E) Performance scale, F) Practical reasoning scale (used only with individuals with a mental age of over 2 years). The raw scores obtained for each scale are transformed into mental ages and then

Table 1: Demographical characteristic of patients.

\begin{tabular}{|c|c|c|c|c|c|}
\hline & \multicolumn{4}{|c|}{$\begin{array}{l}\text { Age class (months) } \\
\text { Mean } \pm \text { sd }\end{array}$} & \\
\hline & & $\begin{array}{c}2,9-8,9 \\
5,36 \pm 2,01\end{array}$ & $\begin{array}{c}9,0-17,9 \\
12,62 \pm 2,43\end{array}$ & $\begin{array}{c}18,0-27,2 \\
21,20 \pm 2,61\end{array}$ & \\
\hline \multirow{2}{*}{ gender } & $\mathrm{M}$ & 5 & 11 & 7 & 23 \\
\hline & $\mathrm{F}$ & 11 & 10 & 11 & 32 \\
\hline
\end{tabular}


converted into specific developmental quotients. A global mental age and a global IQ are obtained by computing the mean of the respective indexes on the six scales.

2) The Vineland Adaptive Behavior Scales, published by Doll in 1935 and then revised by the same author in 1965, is available in an Italian adaptation [39]. It consists of a semi-structured interview with parents or a caregiver. It includes 4 scales that assess different behavior domains; each one includes subscales to assess more specific abilities: communication (expressive, receptive, written); daily living skills (personal, domestic, community); socialization (interpersonal relationships, playing/free time, social rules); and motor skills (gross, fine). The raw scores obtained on each scale are transformed into equivalent ages compared to a normative sample. If the subject being interviewed is over 6 years of age, a deviation IQ score (i.e. a comparison with groups of subjects with intellectual disability) and a "level of adaptive functioning" score is obtained. When the Vineland Scales are used to obtain normative data on subjects with intellectual disability, raw scores must be transformed into deviation IQ and age equivalent scores. As the aim of this study is to describe a specific neuropsychological pattern, it was decided not to transform patients' scores into deviation IQs but rather to use both age-equivalent scores and raw data to describe patients' performances and then to compare them with the performances of the Italian sample of normal subjects.

As normative data are calculated on the survey form, we used the 4 domains and 11 subscale means of the entire sample to estimate average scores for the expanded form.

\section{PROCEDURE}

Each patient's family was provided with a written description of the study and asked to give written informed consent for participation, treatment of personal data and anonymous scientific divulgation. In a preliminary stage, each family was interviewed to collect the patient's anamnestic data, and also received the Vineland Adaptive Behavior Scales. Subsequently, each subject was submitted to a neuropsychological assessment using Griffiths Mental Developmental Scales. On the C Scale, answers given with L.I.S. (Lingua Italiana dei Segni-Italian Sign Language) and AAC (Augmentative Alternative Communication) were accepted. The F Scale (Practical Reasoning Scale) was excluded from the sample analysis because most participants failed to reach the mental age required by this scale.

\section{STATISTICAL ANALYSES}

First, in two separate within-group analyses of variance we compared means IQ of the five Griffiths subscales and age equivalent domain scores from the Vineland scale.

Then two different ANOVAs group (2-9, 10-19, 2028 years) by Griffiths (five levels) or Vineland (4 levels) were performed. Finally a within-group ANOVA was conducted on the Vineland subscales. Post hoc comparisons were made by a Bonferroni-Dunn test when the main effect of factors or interactions reached significance. With a descriptive purpose we compared the proportions of the maximum score obtainable on each Vineland subscale for patients and normative Italian sample.

\section{RESULTS}

The female-to-male ratio was 1.4/1. Mental developmental level was measured by means of

Table 2: Intellectual Disability (DSM-IV-TR Criteria) According to Age-Cohorts

\begin{tabular}{|c|c|c|c|c|}
\hline & \multicolumn{3}{|c|}{ Age class (months) Mean \pm sd } \\
\hline $\begin{array}{l}\text { intell. } \\
\text { disab. }\end{array}$ & $\begin{array}{c}\mathbf{2 , 9 - 8 , 9} \\
\mathbf{5 , 3 6 \pm 2 , 0 1}\end{array}$ & $\begin{array}{c}\mathbf{9 , 0 - 1 7 , 9} \\
\mathbf{1 2 , 6 2} \pm \mathbf{2 , 4 3}\end{array}$ & $\begin{array}{c}\mathbf{1 8 , 0 - 2 7 , 2} \\
\mathbf{2 1 , 2 0 \pm 2 , 6 1}\end{array}$ & \\
\hline \hline mild & 2 & 1 & & $\mathbf{3}$ \\
\hline moderate & 3 & 1 & 2 & $\mathbf{7}$ \\
\hline severe & 1 & 4 & 16 & $\mathbf{4 1}$ \\
\hline profound & 10 & 15 & $\mathbf{1 8}$ & 55 \\
\hline
\end{tabular}


Table 3: Results of Pairwise Comparisons (Significance Levels) for the Griffiths Scales: Means ( \pm sd) are Reported on the Diagonal

\begin{tabular}{|c|c|c|c|c|c|}
\hline & Locomotor & Personal social & $\begin{array}{c}\text { Hearing and } \\
\text { language }\end{array}$ & $\begin{array}{c}\text { Hand-eye } \\
\text { coordination }\end{array}$ & performance \\
\hline \hline Locomotor & $15.84( \pm 14.04)$ & $<.05$ & $\mathrm{~ns}$ & $<.05$ & $\mathrm{~ns}$ \\
\hline Personal social & & $18.02( \pm 17.76)$ & $\mathrm{ns}$ & $<.001$ & $<.001$ \\
\hline Hearing and language & & & $18.85( \pm 16.3)$ & $<.001$ & $\mathrm{~ns}$ \\
\hline Hand-eye coordination & & & & $13.66( \pm 14.37)$ & $13.93( \pm 14.38)$ \\
\hline performance & & & & & \\
\hline
\end{tabular}

Griffiths total IQ and classified on the basis of the DSMIV-TR criteria [42]. Intellectual disability was mild in $5 \%$, moderate in $7 \%$, severe in $13 \%$ and profound in $75 \%$ of cases. In Table 2 frequencies according to age group and intellectual disability are shown.

In order to confirm the existence of a WHS Neuropsychological Phenotype, all differences in the various abilities of each subject were analyzed. IQ scores were used for each of Griffiths subscales. For the Vineland scale, age equivalent scores for each domain and for each subscale were used, as well as mean raw scores in order to compare patients with a normative Italian sample.

Significant differences emerged for performances in the five ability domains $\left(F_{(4,216)}=12.54, \quad p<.0001\right)$ evaluated with Griffiths Mental Developmental Scales, providing evidence of a specific WHS neuropsychological phenotype. In Table 3 means with standard deviations and significance levels of each pair wise comparison are summarized.
Mean IQ comparisons showed "strengths" in the personal-social area (B scale: mean 18.02 \pm 17.76), which were significantly stronger than motor skills $(p<.05)$, coordination and performance scales (for both comparisons, $p<.001)$ with the exception of communication abilities (C scale: mean 16.85 \pm 16.3). Communication abilities were also significantly better than coordination skills and non-verbal abilities (mean $13.66 \pm 14.37$ and $13.93 \pm 14.38$, respectively, $p<.001$ for both comparisons). No significant difference emerged between the $\mathrm{C}$ scale and motor development skills (A scale: mean 15.84 \pm 14.04 ). The lowest scores were obtained for coordination and non-verbal skills, which did not differ from each other. Means ( \pm se) for each Griffiths IQ subscale are presented in Figure 1.

Given the large age variability of our sample, we compared performances in the five domains according to three age cohorts: 2-8, 9-17, 18-28 years. The ANOVA with age ( 3 groups) as independent factor and "Griffiths" (5 scales) as repeated factor showed the main effects of age $\left(F_{(2,52)}=3.6, p<.05\right)$ and Griffiths

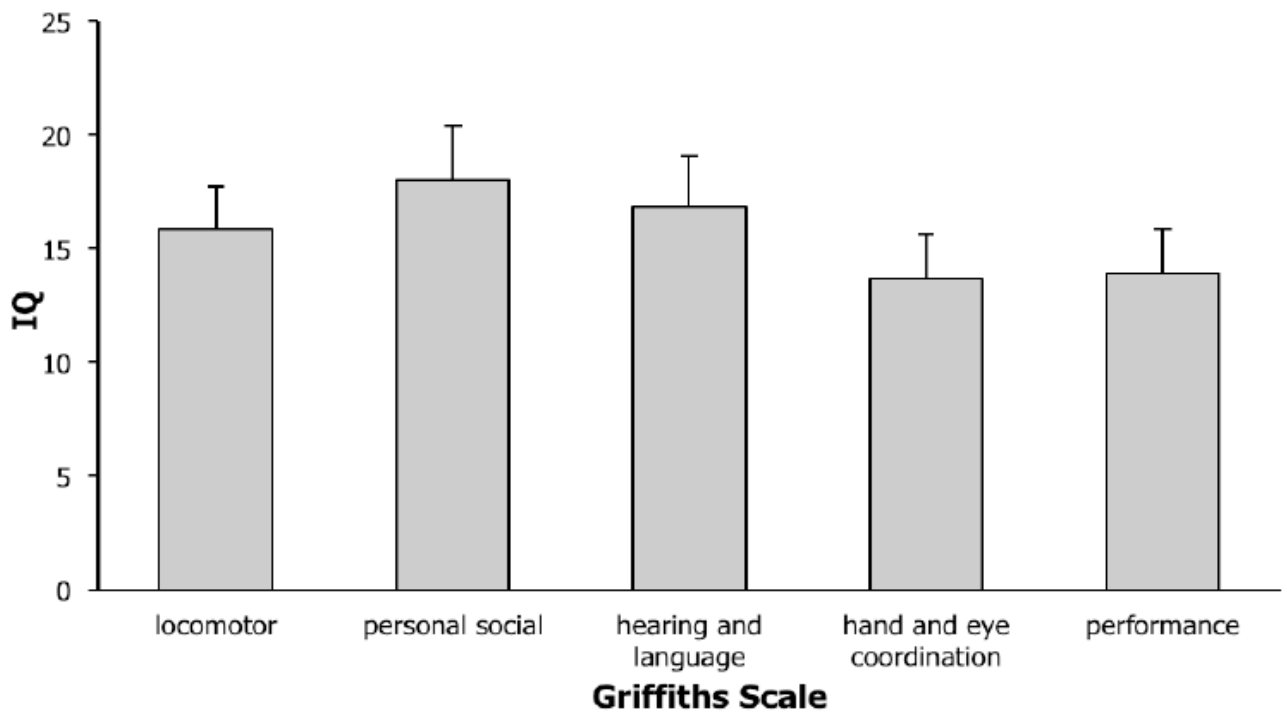

Figure 1: Means and standard errors for each GRIFFITHS IQ subscale. 


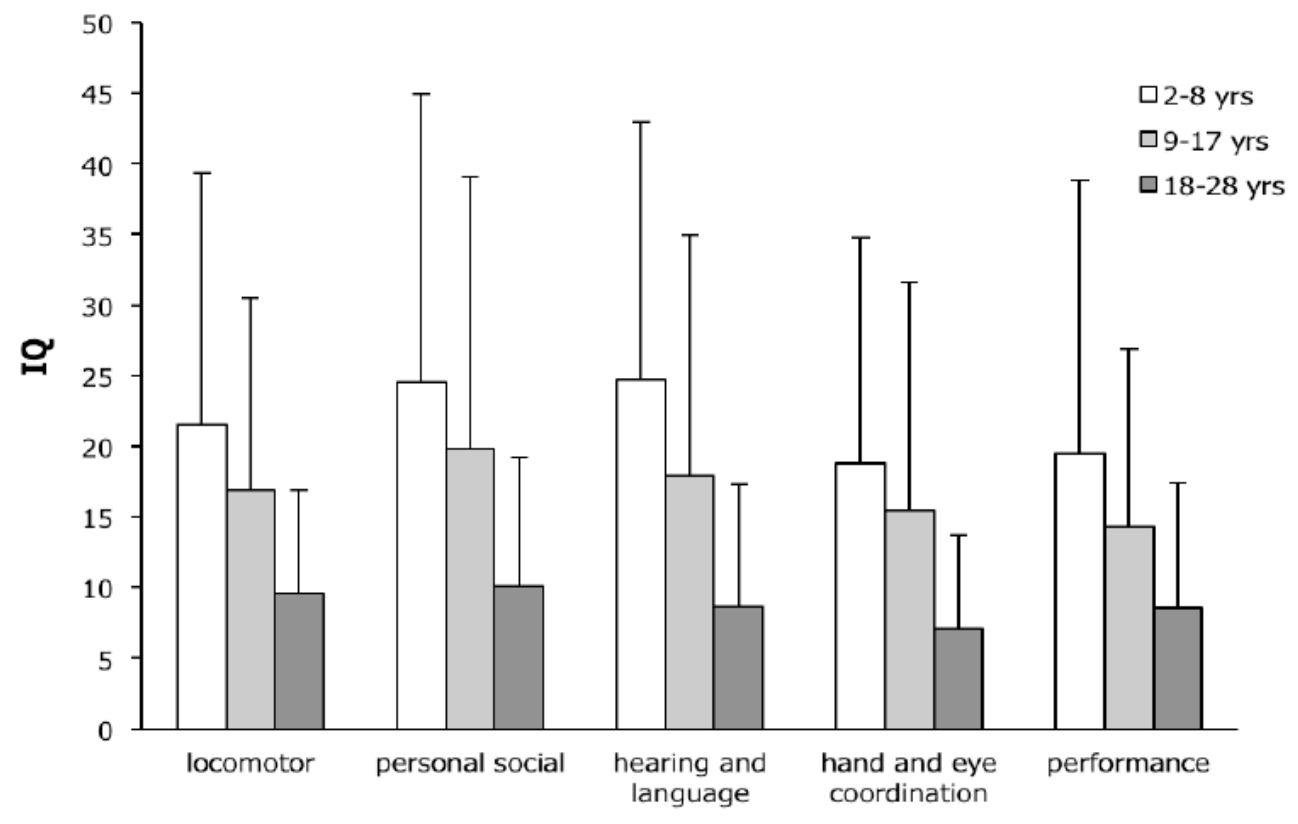

Griffiths Scale

Figure 2: Means and standard deviations for each GRIFFITHS IQ subscale according to the three age cohorts.

$\left(F_{(4,208)}=12.97, \quad p<.0001\right)$. The same pattern was confirmed in all age cohorts: the younger group had higher IQ scores $(21.8 \pm 18.34)$ than the other two groups ( $16.87 \pm 15,78$ and $8.79 \pm 8.13$, respectively), while only the difference between group 1 (2-8 years) and 3 (18-28 years) was significant $(p<.05)$. The interaction was not significant $\left(\mathrm{F}_{(8,208)}=1.69\right.$, ns $)$. In Figure 2 means and standard deviations for each Griffiths IQ subscale according to the three age cohorts are presented.
For the Vineland Adaptive Behavior Scales, ageequivalent scores were used for the first comparison. Figure 3 reports means (and standard errors) for ageequivalent scores.

Significant performance differences were discovered in the four ability areas $\left(F_{(3,162)}=16.05\right.$, $\mathrm{p}<.0001)$. Mean comparisons established that the best performances were obtained on the Socialization scale (34.04 \pm 39.43$)$, that showed a significantly higher ageequivalent score than the Communication

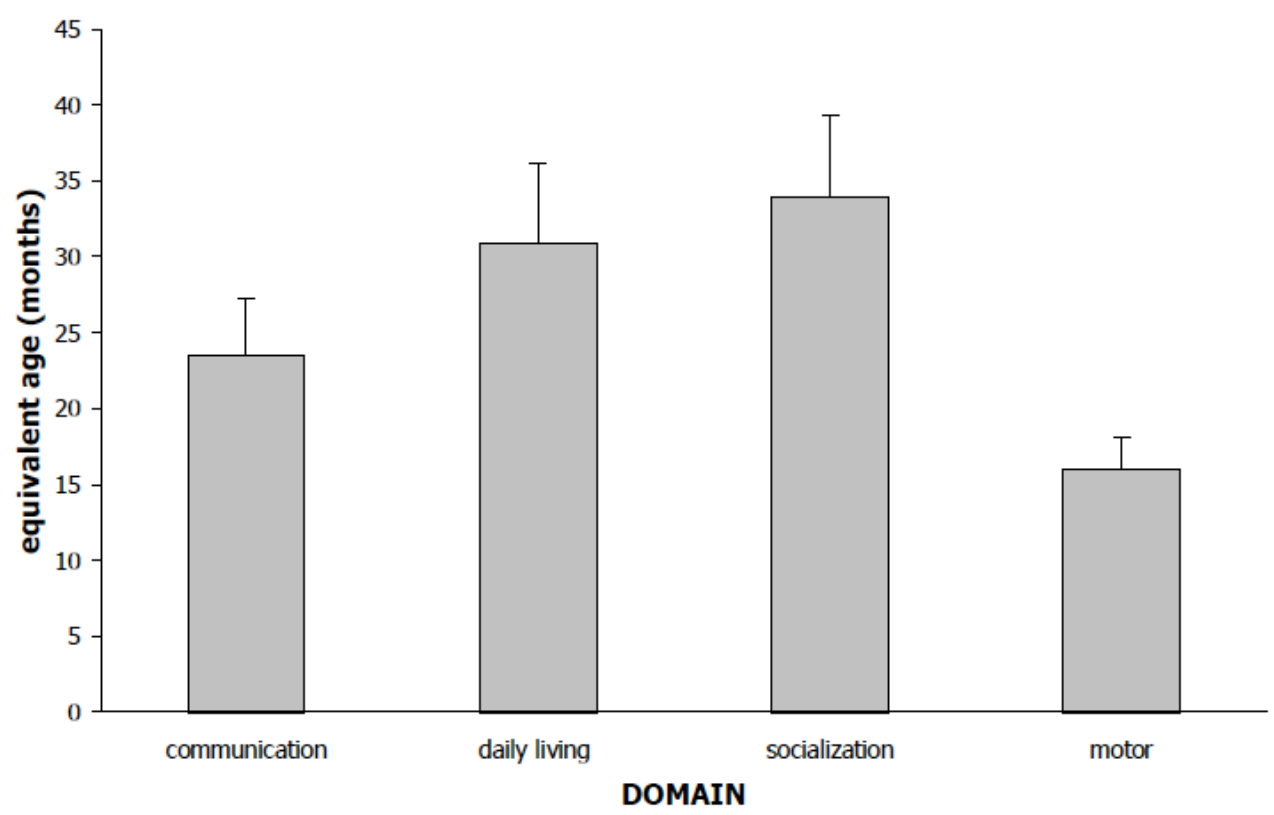

Figure 3: Means and standard errors for VINELAND age equivalent scores. 


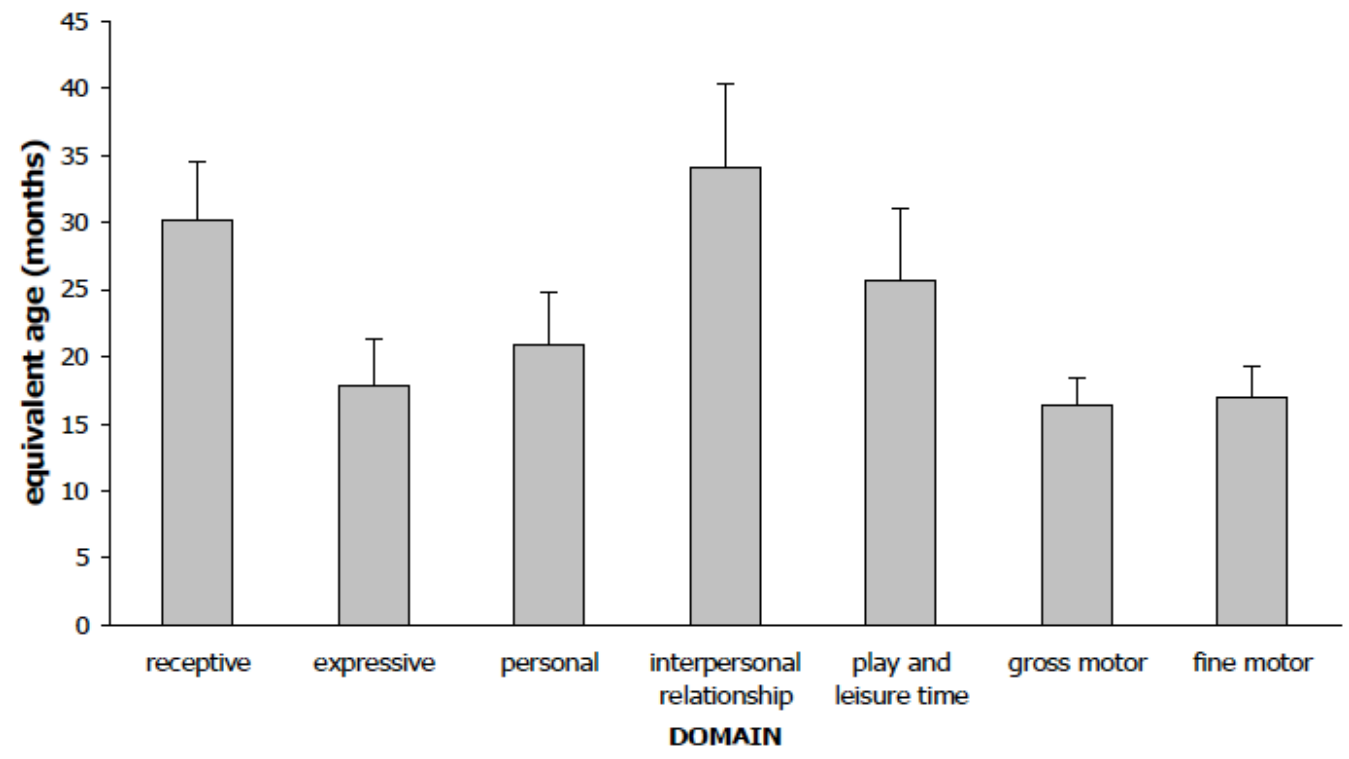

Figure 4: Means and standard errors for Vineland equivalent age score.

(23.58 $\pm 27.75, p=.002)$ and the Motor development scales $(16.07 \pm 14.88, p<.0001)$. The mean ageequivalent score for daily living abilities $(30.95 \pm 38.99)$ was significantly higher than those of both the communication (even if the difference did not reach significance, $p=.06)$ and motor competence $(p<.001)$ domains.

Also for these scales, age-equivalent scores were compared according to the three age groups. The ANOVA with age ( 3 groups) by "Vineland" ( 4 scales) highlighted the main effect of Vineland factor $\left(F_{(3,156)}=\right.$ 14.89, $\mathrm{p}<.0001)$. Comparisons between means reproduced the same pattern described before when the four age-equivalent scores were analyzed. Differences between groups $\left(\mathrm{F}_{(2,52)}=2.14\right.$, ns $)$ and the interaction $\left(F_{(6,156)}=1.68\right.$, ns) were not significant.

Due to the absence of differences in the group profiles, subsequent analyses were conducted on the entire sample.
In order to obtain a more accurate description of patients' interactive performances, subscale scores were compared. It was impossible for all 11 subscales in the four domains to be considered as some contained a high number of zero scores. For some abilities, this occurred because the raw score fell outside the age equivalent range (domestic, community and social rules sub-domains) or the individuals were too young to perform the activity (written sub-domain). Age-equivalent scores are presented in Figure 4.

Performances on the 7 subscales were significantly different $\left(F_{(6,324)}=7.68, p<.0001\right.$. Table 4 summarize the means with standard deviations and significance levels of each pairwise comparison.

The highest scores referred to the interpersonal relationship (34.04 \pm 47.1$)$ and receptive $(30.2 \pm 32.16)$ subscales, which were not significantly different from each other or from the play subscale $(25.73 \pm 14.99)$. The interpersonal relationship sub-domain differed significantly from the expressive $(17.89 \pm 11.09, \mathrm{p}<001)$

Table 4: Results of Pairwise Comparisons (Significance Levels) for the Vineland Subscales: Means ( \pm sd) are Reported on the Diagonal

\begin{tabular}{|c|c|c|c|c|c|}
\hline & Receptive & Expressive & personal & interpersonal & $\mathrm{ns}$ \\
\hline \hline Receptive & $30.2( \pm 32.16)$ & $<.05$ & $\mathrm{~ns}$ & $\mathrm{~ns}$ & $\mathrm{~ns}$ \\
\hline Expressive & & $17.89( \pm 11.09)$ & $\mathrm{ns}$ & $=.006$ & $\mathrm{~ns}$ \\
\hline personal & & & $20.89( \pm 13.09)$ & $34.04( \pm 47.1)$ & $\mathrm{ns}$ \\
\hline interpersonal & & & & & $25.73( \pm 14.99)$ \\
\hline play & & & & & \\
\hline
\end{tabular}




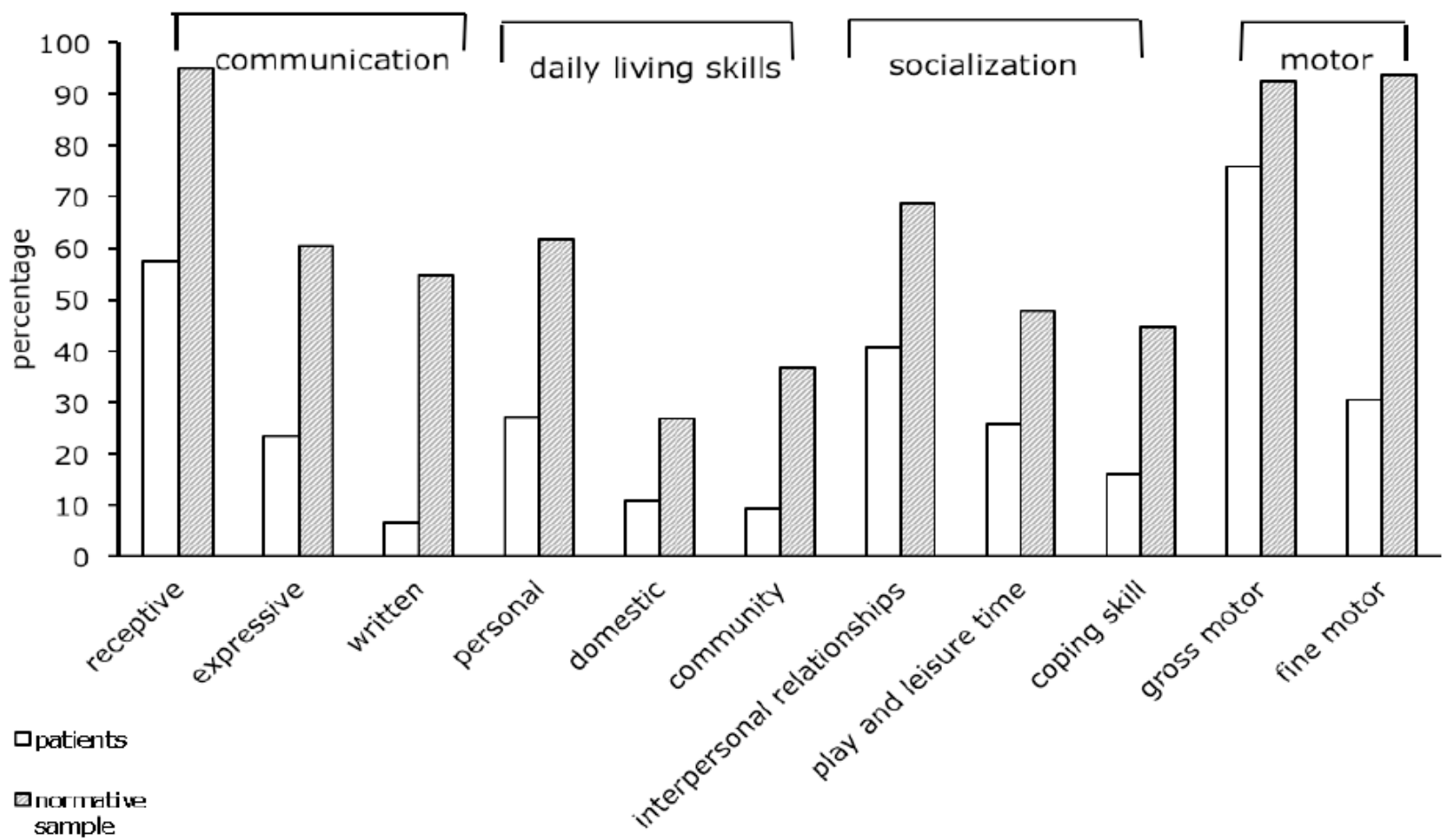

Figure 5: Percentage of the maximum score obtainable in each Vineland subscale (both for patients and controls).

and the personal $(20.89 \pm 13.09, p=.006)$ scales. Receptive abilities were different from expressive subdomain $(p<.05)$. Motor scores were not considered in these comparisons since the nature of these skills have little in common with the social aspects of the other above mentioned abilities.

It was not feasible to make a direct comparison of patients' scores with normative data because of the very large variability in patients' performances. To obtain a descriptive comparison between patients and normal controls, we expressed the different means (both for patients and controls) in terms of proportion of the maximum score obtainable on each subscale taken into consideration. As normative data were collected using the survey form of the scale, long-form means were estimated starting from the values of the short scale. Moreover, it was decided not to take into account the different age classes of the normative sample because of the large age differences between patients. We used the whole sample means. Results are presented in Figure $\mathbf{5}$.

As shown in the figure, normal subjects did not reach the maximum score in any subscale.

The major ratios between patients and controls were related to social abilities (interpersonal relationships and receptive skills).

\section{DISCUSSION}

There is now evidence that patients with WHS reach higher developmental levels than those reported in the literature $[18,35,43]$. Furthermore, the cognitive profile of WHS patients appears to be specific [30,31]. Although a considerable within-syndrome variability there is evidence of a relative strength in social skills compared with other cognitive domains. This study was designed to identify and describe a neuropsychological phenotype for this syndrome. Note that although the number of subjects seems very small, almost the entire Italian population of WHS patients (approximately $70 \%$ ) was contacted. Nevertheless, the collected data constitute the first attempt to obtain systematic measures in a large sample of WHS patients. This is a point that seems important to stress. The use of reliable tools is crucial to ensure the reproducibility of results and comparison between different groups of patients. Recently a few studies systematically analyzed the specific characteristics of the neuropsychological profile of WHS [3, 30, 31, 36, 44]. Although the patients' samples examined and the procedures were different, results seem to lead to the identification of a typical WHS cognitive-behavioral profile: patients exhibited some strength in socialization abilities and communicative skills. From our point of view, an assessment that clarifies areas of strength and weakness allows the level of developmental 
competence of different neuropsychological functions to be better defined and is thus useful for planning habilitation programs aimed at building upon specific residual abilities [45]. The only drawback of this approach is the small number of patients affected by a rare syndrome and the high variability often present between subjects.

Our results can be summarized as follows: we found a behavioral dissociation between communication and social interaction skills and perceptual and visual-motor abilities. Despite their severe cognitive impairment, our WHS patients showed significant strength in the socialization domain of both scales used. This finding was described in a previous paper [36] for performances evaluated using Griffiths scales, and here the same trend was confirmed using the Vineland socialization scale. This is in agreement with data reported by other authors $[30,31,44]$.

A similar result was obtained for communication abilities on both the Griffiths ( $\mathrm{C}$ scale) and the Vineland scale. On the latter, much of the score was due to receptive and expressive sub-domains, because on the written subscale $75 \%$ of the subjects obtained a score of zero (no skill). The receptive subscale also showed a higher ratio when patients' and controls' scores were compared.

As expected, coordination and non-verbal abilities were the most compromised together with the abilities tested in the motor domain of the Vineland scale. Considering the gross and fine motor subscales, it is clear that major deficits in fine motor abilities were present when patients and normal subjects were compared.

In brief, although many patients showed much compromised coordination skills and non-verbal abilities, they revealed a less severe picture in the sphere of social and personal skills and communicative competencies. This profile seems typical throughout the lifetime of these individuals, as demonstrated by the similar results obtained by the different age subgroups considered in this study.

Some limitations of our study should be taken into account. In WHS, as in any rare disorder, the paucity of patients makes it very difficult to identify a reliable profile. There are several reasons for this. We already mentioned the great variability that characterizes these patients. The instruments used to assess cognitive performances are often insensitive for detecting the very "low" presence of a skill in patients with very severe deficits. In their study, Sabbadini et al. [46] stated that the traditional instruments are inadequate for differentiating the various degrees of functional impairment. In fact, normative data are not expected to discriminate between scores below a certain cutoff because they are too rare in the normal population. Moreover, as some skills (see motor development in the Vineland Scale) reach their peak by a specific age, there is a lack of variability in the raw scores of the standardization sample beyond this age. Consequently, derived scores, such as equivalent age scores or deviation IQs, do not have a wide enough range to be used for impaired individuals. Therefore, the same scores are assigned to patients with very different abilities and no differences emerge among patients with severe impairments. Furthermore, in the present study more than $50 \%$ of the patients fell below the lowest score of the normative groups. Therefore, in the Vineland scale when the raw scores were transformed into equivalent age scores on the basis of normative data, many patients obtained the same scores. To avoid this problem and to be able to describe the performances of all our patients, we made a proportional calculation of the corresponding ageequivalence for scores lower than the minimal values reported in the manual. Patients' performances in some skill areas were much worse than in others and a very low equivalent age emerged. However, this made it possible to obtain a descriptive frame also for these very poor abilities.

In the Vineland Scale, normative data are provided for pathological samples. However, these groups may be very different from the patients being studied (especially when the disease is very rare). Therefore, it seemed more appropriate to use raw scores to identify the cognitive profile of this rare syndrome because they enable the entire range of values to be used and avoid the flattening of the distribution for the lowest values. As a consequence, it was decided to adopt this procedure for the Vineland Scale since it is more suitable for obtaining a detailed description of patients' behaviors.

Comparing groups with different genetic disorders would have been more proper, but given our sample size it would have been very difficult to have equivalent groups.

Although we were aware of the limits of this method (it is rather coarse), our primary aim was to describe the specific pattern of WHS patients' abilities compared 
to those of the control subjects. Comparisons between patients and controls showed that the patients' scores for those abilities which had been preserved (relative to their relational capacities) were not so different from the normative data when age differences were not considered.

These results confirm the presence of a WHS neuropsychological phenotype characterized by specific strengths and weaknesses. In particular, communication and personal social abilities are always better than coordination and non-verbal abilities.

The fact that a specific pattern of abilities/disabilities seems to be present always, supports the notion that the neuropsychological profile of this syndrome is stable and very typical.

These results have important implications for planning specific, targeted rehabilitation interventions.

The latent communication abilities of these patients should also be considered in planning treatment interventions. Although patients with WHS often have severe speech deficits, they are able to express themselves, communicate and interact by showing their intention to communicate. In this view, it would be helpful to evaluate the effectiveness of introducing augmentative alternative systems. Indeed, from the very beginning of child development it is essential to empower the spectrum and meaning of gestures to facilitate communication, interaction, and active participation, and positively to stimulate growth by expanding the child's ability to act on the environment.

Another issue is related to visual coordination and motor impairments. Despite their desire to communicate and participate, children with WHS might be so severely impaired that they are unable to develop the motivation to communicate and participate. Patients who are unable to maintain eye contact or even to look at the person talking to them are unable to understand others' verbal and non-verbal communication. If patients have no control over their own movements or the changes that are occurring simultaneously in the surrounding environment and if they are also unable to focus their attention, they might be erroneously considered to have no interest in social interaction and communication.

It is likely that attentional deficits and poor eye contact, difficulty in perception, coordination and visual motor integration have such a negative effect on their performance that these children are unable to achieve adequate contextual comprehension. Consequently, their behavior may be misunderstood. Therefore, specific training aimed at improving the development of attention abilities, nonverbal competencies and communication skills is recommended in the rehabilitation program.

In conclusion, this study is the first to present a comprehensive picture of the Italian population of certified WHS patients. Even with some limitations, this work represents an important landmark in research on patients with WHS. Future studies will be devoted to obtaining more accurate quantifications of the neuropsychological phenotype, whit final aim is to improve diagnosis and create specific rehabilitative interventions.

\section{ACKNOWLEDGEMENTS}

We wish to express our gratitude to Dr. Maria Rosa Pizzamiglio and to Dr. Stefano Paolucci for their critical support throughout the project. Special thanks also to the WHS individuals and their families.

\section{REFERENCES}

[1] Battaglia A, Carey JC, Cederholm P, Viskochil DH, Brothman AR, Galasso C. Natural history of Wolf-Hirschhorn syndrome: experience with 15 cases. Pediatrics 1999; 103(4 Pt 1): 830836.

http://dx.doi.org/10.1542/peds.103.4.830

[2] Hirschhorn, K. A short history of the initial discovery of the Wolf-Hirschhorn syndrome. Am J Med Genet Part C Semin Med Genet 2008; 148C(4): 244-245. http://dx.doi.org/10.1002/ajmg.c.30186

[3] Battaglia A, Filippi T, Carey JC. Update on the clinical features and natural history of Wolf-Hirschhorn (4p-) syndrome: experience with 87 patients and recommendations for routine health supervision. Am J Med Genet C Semin Med Genet 2008; 148C(4): 246-251. http://dx.doi.org/10.1002/ajmg.c.30187

[4] Basgul A, Kavak ZN, Akman I, Basgul A, Gokaslan H, Elcioglu N. Prenatal diagnosis of Wolf-Hirschhorn syndrome $(4 p-)$ in association with congenital diaphragmatic hernia, cystic hygroma and IUGR. Clin Exp Obstet Gynecol 2006; 33(2): 105-106.

[5] De Keersmaecker B, Albert M, Hillion Y, Ville Y. Prenatal diagnosis of brain abnormalities in Wolf-Hirschhorn (4p-) syndrome. Prenat Diagn 2002; 22(5): 366-370.

http://dx.doi.org/10.1002/pd.318

[6] Zollino $M$, Lecce $R$, Fischetto $R$, et al. Mapping the WolfHirschhorn syndrome phenotype outside the currently accepted WHS critical region and defining a new critical region, WHSCR-2. Am J Hum Genet 2003; 72(3): 590-597. http://dx.doi.org/10.1086/367925

[7] Dietze I, Fritz B, Huhle D, Simoens W, \& Piecha E, Rehder $\mathrm{H}$. Clinical cytogenetic and molecular investigation in a fetus with Wolf-Hirschhorn syndrome with paternally derived $4 p$ deletion. Case report and review of the literature. Fetal Diagn and Ther 2004; 19(3): 251-260.

http://dx.doi.org/10.1159/000076707 
[8] Zollino M, Di Stefano C, Zampino G, et al. GenotypePhenotype correlations and clinical diagnostic criteria in WolfHirschhorn syndrome. Am J Hum Genet 2000; 94(3): 254261.

http://dx.doi.org/10.1002/1096

8628(20000918)94:3<254::AID-AJMG13>3.0.CO;2-7

[9] Wilson MG, Towner JW, Coffin GS, Ebbin AJ, Siris E, Brager $P$. Genetic and clinical studies in 13 patients with the WolfHirschhorn syndrome (del 4p-). Hum Genet 1981; 59(4): 297307.

http://dx.doi.org/10.1007/BF00295461

[10] Zollino M, Wright TJ, Di Stefano C, et al. "Tandem" duplication of $4 \mathrm{p} 16.1 \mathrm{p} 16.3 \mathrm{pter}$ chromosome region associated with $4 \mathrm{p} 16.3$ pter molecular deletion resulting in Wolf-Hirschhorn syndrome phenotype. Am J Hum Genet 1999; 82(5): 371-375. http://dx.doi.org/10.1002/(SICI)10968628(19990219)82:5<371::AID-AJMG3>3.0.CO;2-J

[11] Syrrou M, Borghgraef M, and Fryns JP. Unusual Mosaicism in Wolf-Hirschhorn Syndrome. Am J Med Genet 2001; 104(3): 199-203.

http://dx.doi.org/10.1002/10968628(20011201)104:3<199::AID-AJMG10058>3.0.CO;2-4

[12] Lurie IW, Lazjuk GI, Ussova YI, Presman EB, Gurevich DB. The Wolf-Hirschhorn syndrome. I. Genetics. Clin Genet 1980; 17(6): 375-384 http://dx.doi.org/10.1111/j.1399-0004.1980.tb00167.x

[13] Shannon NL, Maltby EL, Rigby AS, Quarrell OW. An epidemiological study of Wolf-Hirschhorn syndrome: life expectancy and cause of mortality. Journal of Medical Genetics 2001; 38(10): 674-679.

http://dx.doi.org/10.1136/jmg.38.10.674

[14] Maas NM, Van Buggenhout G, Hannes F, et al. Genotypephenotype correlation in 21 patients with Wolf-Hirschhorn syndrome using high resolution array comparative genome hybridisation (CGH). J Med Genet 2008; 45(2): 71-80.

http://dx.doi.org/10.1136/jmg.2007.052910

[15] Babich SB, Banducci C, Teplitsky P. Dental characteristics of the Wolf-Hirschhorn syndrome: a case report. Spec Care Dentist 2004; 24(4): 229-231.

http://dx.doi.org/10.1111/j.1754-4505.2004.tb01697.x

[16] Antonius T, Draaisma J, Levtchenko E, Knoers N, Renier W, van Ravenswaaij C. Growth charts for Wolf-Hirschhorn syndrome (0-4 years of age). Eur J Pediatr 2008; 167(7): 807-810.

http://dx.doi.org/10.1007/s00431-007-0595-8

[17] Concolino D, Rossi E, Strisciuglio P, Lembo MA, Giorda R, Ciccone R, Tentoni R Zuffardi O. Deletion of a $760 \mathrm{~kb}$ region at $4 p 16$ determines the prenatal and postnatal growth retardation characteristic of Wolf-Hirschhorn syndrome. Journal of Medical Genetics 2007; 44(10): 647-650. http://dx.doi.org/10.1136/jmg.2007.050963

[18] Battaglia A, Carey JC, Wright TJ. Wolf-Hirschhorn (4p-) Syndrome. Adv pediatr 2001; 48: 75-113.

[19] Schaefer BG, Kleimola CN, Stenson C, Daley SE, Farmer P, Holladay K. Wolf-Hirschhorn Sindrome (deletion 4p): A guidebook for families. Omaha, NE, RD \& Meyer Rehabilitation Institute, University of Nebraska Medical Center, 1996.

[20] Aslan H, Karaca N, Basaran S, Ermis H, Ceylan Y. Prenatal diagnosis of Wolf Hirschhorn syndrome (4p-) in association with congenital hypospadias and foot deformity. BMC Pregnancy Childbirth 2003; 3: 1-6. http://dx.doi.org/10.1186/1471-2393-3-1

[21] Lazjuk GI, Lurie IW, Ostrowskaja TI, et al. The WolfHirschhorn syndrome. II. Pathologic anatomy. Clin Genet 1980; 18(1): 6-12.

http://dx.doi.org/10.1111/j.1399-0004.1980.tb01357.x
[22] Ulualp S, Wright C, Pawlowski K, Roland P. Histopathological basis of hearing impairment in Wolf-Hirschhorn Syndrome. Laryngoscope 2004; 114(8): 1426-1430. http://dx.doi.org/10.1097/00005537-200408000-00021

[23] Battaglia A \& Carey JC. Seizure and EEG patterns in WolfHirschhorn (4p-) syndrome. Brain Dev 2005; 27(5): 362-364. http://dx.doi.org/10.1016/j.braindev.2004.02.017

[24] Kagitani-Shimono K, Imai K, Otani K, et al. Epilepsy in WolfHirschhorn syndrome (4p-). Epilepsia 2005; 46(1): 150-155. http://dx.doi.org/10.1111/j.0013-9580.2005.02804.x

[25] Righini A, Ciosci R, Selicorni A, et al. Brain magnetic resonance imaging in Wolf-Hirschhorn syndrome. Neuropediatrics 2007; 38(1): 25-28. http://dx.doi.org/10.1055/s-2007-981685

[26] Battaglia A. Sindrome di Wolf-Hirschhorn (4p-): una causa di ritardo mentale grave di difficile diagnosi. Rivista italiana di pediatria 1997; 23: 254-259.

[27] Wieczorek D, Krause M, Majewski F, et al. Effect of the size of the deletion and clinical manifestation in Wolf-Hirschhorn syndrome: analysis of 13 patients with a de novo deletion. Eur J Hum Genet 2000; 8(7): 519-526. http://dx.doi.org/10.1038/sj.ejhg.5200498

[28] Battaglia A, Filippi T, South ST, Carey JC. Spectrum of epilepsy and electroencephalogram patterns in WolfHirschhorn syndrome: experience with 87 patients. Dev Med Child Neurol 2009; 51(5): 337-338. http://dx.doi.org/10.1111/j.1469-8749.2008.03233.x

[29] Battaglia D, Zampino G, Zollino M, Mariotti $P$, et al. Electroclinical patterns and evolution of epilepsy in the $4 p$ syndrome. Epilepsia 2003; 44(9): 1183-1190. http://dx.doi.org/10.1046/j.1528-1157.2003.63502.x

[30] Fisch GS, Battaglia A, Parrini B, Youngblom J, Simensen R. Cognitive-behavioral features of children with WolfHirschhorn syndrome: preliminary report of 12 cases. Am J Med Genet C Sem Med Genet 2008; 148C(4): 252-256. http://dx.doi.org/10.1002/ajmg.c.30185

[31] Fisch GS, Grossfeld P, Falk R, Battaglia A, Youngblom J, Simensen R. Cognitive-behavioral features of Wolf Hirschhorn syndrome and other subtelomeric microdeletions. Am J Med Genet C Semin Med Genet 2010; 154C(4): 417426.

http://dx.doi.org/10.1002/ajmg.c.30279

[32] Thomson P. Wolf-Hirschhorn syndrome. Review of the literature and three case studies. J Am Podiatr Med Assoc 1998; 88(4): 192-197. http://dx.doi.org/10.7547/87507315-88-4-192

[33] Kozma C, Chong SS, Meck JM. Interstitial deletion of $4 p 15.32 p 16.3$ in a boy with minor anomalies, hearing loss, borderline intelligence, and oligodontia. Am J Med Genet 1999; 86(4): 316-320.

http://dx.doi.org/10.1002/(SICI)1096 8628(19991008)86:4<316::AID-AJMG3>3.0.CO;2-1

[34] Ji TY, Chia D, Wang JM, Wu Y, Li J, Xiao J, Jiang YW. Diagnosis and fine localization of deletion region in WolfHirschhorn syndrome patients. Chin Med J (Engl) 2010; 123(13): 1663-1667.

[35] Marcelis C, Schrander-Stumpel C, Engelen J, et al. WolfHirschhorn (4P-) syndrome in adults. Genetic Counseling 2001; 12(1): 35-48.

[36] Cossu MC, Morelli D, Antonucci A. Studio su una popolazione di 57 casi di sindrome di Wolf-Hirschhorn: esiste una variabilità del profilo cognitivo nella WHS? Psicologia Clinica e dello Sviluppo 2011; 2: 449-469.

[37] Griffiths R. The abilities of young children. A comprehensive system of mental measurement for the first eight years of life. London, England: Child Development Research Centre 1970. 
[38] Griffiths R. The abilities of young children. A comprehensive system of mental measurement for the first eight years of life. London: the Test Agency 1984.

[39] Balboni G, Pedrabissi L. Adattamento italiano delle Vineland Adaptive Behavior Scales. Firenze: O.S. Organizzazioni Speciali 2003.

[40] Andersen WH, Rasmussen RK, Strømme P. Levels of cognitive and linguistic development in Angelman syndrome: a study of 20 children. Logoped Phoniatr 2001; 26(1): 2-9. http://dx.doi.org/10.1080/140154301300109044

[41] Madden SJ, Ledermann SE, Guerrero-Blanco M, Bruce M. Cognitive and psychosocial outcome of infants dialysed in infancy. Trompeter RS. Child Care Health Dev 2003; 29(1): $55-61$.

http://dx.doi.org/10.1046/j.1365-2214.2003.00311.x

[42] DSM-IV-TR. Diagnostic and Statistical Manual of Mental Disorders. IV edition, Text Revision. Washington, DC: American Psychiatric Association 2000.
[43] Partington M, Turner G. Wolf-Hirschhorn and Pitt-RogersDanks syndromes. Am J Med Genet 1999; 82(1): 88-90. http://dx.doi.org/10.1002/(SICl)1096 8628(19990101)82:1<88::AID-AJMG17>3.0.CO:2-0

[44] McGill P, Langthorne P. Investigation of adaptive and maladaptive behavior in people with Wolf-Hirschhorn Syndrome. Canterbury: Tizard Centre 2009.

[45] Pizzamiglio MR. La Riabilitazione neuropsicologica in età evolutiva. Ed. Franco Angeli 2003.

[46] Sabbadini M, Bombardi P, Carlesimo GA, Rosato V, Pierro $M$. Evaluation of communicative and functional abilities in Wolf-Hirshhorn syndrome. J Intellect Disabil Res 2002; 46(Pt 7): 575-82. http://dx.doi.org/10.1046/.1365-2788.2002.00441.x 